\title{
What does galvanic vestibular stimulation actually activate?
}

\author{
Bernard Cohen ${ }^{1}$, Sergei B. Yakushin ${ }^{1}$ and Gay R. Holstein ${ }^{1,2,3}$ \\ Department of Neurology, Mount Sinai School of Medicine, New York, NY, USA \\ 2 Department of Neuroscience, Mount Sinai School of Medicine, New York, NY, USA \\ ${ }^{3}$ Department of Anatomy/Functional Morphology, Mount Sinai School of Medicine, New York, NY, USA \\ *Correspondence: bernard.cohen@mssm.edu
}

Luigi Galvani spent 20 years conducting experiments to demonstrate electrical conductivity of nerves and muscles before publishing his major treatise on the subject in 1791 (Galvani, 1791). His personal friend and professional nemesis Count Alessandro Volta held a respectful but opposing view, that nerve and muscle tissues simply serve as passive conductors, and he built the first "voltaic" battery in an attempt to prove his point. Ultimately it appears that they were both partially correct, and the same bioelectric potentials sought by Galvani and debunked by Volta continue to be used in present day because they are an easy, noninvasive approach to activate the vestibular nerve(s). Yet, debate continues in contemporary medicine and science regarding the exact effect of galvanic stimulation on the nervous system.

Galvanic vestibular stimulation (GVS) has been used to activate fibers of the vestibular nerve in humans and experimental animals by applying $0.1-4 \mathrm{~mA} \mathrm{DC}$ currents through the skin over the mastoid processes (for reviews, see Fitzpatrick and Day, 2004; Curthoys, 2009). Steps of current are used most often, causing continuous activation of the entire vestibular nerve, particularly those fibers with irregular spontaneous firing rates (Goldberg et al., 1984; Minor and Goldberg, 1991). This stimulation excites a wide range of central vestibular neurons, including those related to both the semicircular canals and the otolith organs (Wilson et al., 1979; Peterson et al., 1980; Ezure et al., 1983; Courjon et al., 1987). However, despite this non-selective activation, it appears that only otolith-related behavioral responses are induced. Human subjects experience sensations of rocking or pitching, head and/or body tilt, and have ocular torsion - all characteristics of otolith system activation (Zink et al., 1997; Watson et al., 1998; Séverac Cauquil et al., 2003; Macdougall et al., 2005; Bent et al., 2006). They do not experience sensations of rotation and do not display ocular nystagmus, which would occur if the semicircular canals were continuously stimulated (Mach, 1875; Cohen et al., 1965; Guedry, 1974). This apparent paradox has engendered considerable controversy: does GVS primarily or exclusively activate the otolith system, or does it activate both the otolith and semicircular canal systems equivalently?

The preponderance of physiological data support the view that GVS is primarily an otolithic stimulus. A variant of GVS utilizing binaurally applied sinusoidal currents (sinusoidal GVS, sGVS) was introduced by Macefield and colleagues (Bent et al., 2006; Grewal et al., 2009; James and Macefield, 2010; James et al., 2010), and has proven to be a potent technique for inducing muscle sympathetic nerve activity (MSNA) in the legs of humans. MSNA causes peripheral vasoconstriction, which maintains adequate blood supply to the brain upon standing. This orthostatic response is clearly associated with the otolith system (Yates, 1992; Woodring et al., 1997; Kerman et al., 2003). When sGVS is applied to anesthetized rats, it can also induce sudden decreases in blood pressure and heart rate that resemble human vasovagal syncope (Cohen et al., 2011). Similar sustained drops in blood pressure have been shown in alert and anesthetized rats after linear acceleration (Zhu et al., 2007). sGVS also evokes frequencydependent postural sway in standing subjects, further supporting the idea that the stimulus primarily activates the otolith system (Lau et al., 2003).

Functional anatomical studies have also contributed to the controversy regarding the neural effect(s) of GVS. These investigations have utilized GVS to induce activation of the immediate early gene $c$-fos, and to visualize its protein product c-Fos, which accumulates in the nuclei of activated neurons. Steps of GVS applied unilaterally to rodents result in bilateral c-Fos expression near the ventricular wall in the medial vestibular nucleus (MVN), with muted expression in the inferior vestibular nucleus (IVN) and no c-Fos accumulation in the superior or lateral vestibular nuclei (SVN and LVN, respectively; Kaufman and Perachio, 1994; Marshburn et al., 1997; Abe et al., 2009). In this Frontiers Special Topic, Holstein and colleagues report that sGVS in rats results in c-Fos accumulation in some neurons in caudal IVN, in cells of the parasolitary nucleus, in neurons throughout MVN, and in cells located in a small medial wedge in caudal SVN. There were no activated neurons in the portions of the vestibular nuclear complex (VNC) that participate directly in the horizontal and vertical vestibulo-ocular reflexes, or the vestibulo-spinal postural reflexes. These studies reflect the same apparent contradiction evident in human physiological investigations: if GVS activates the entire vestibular nerve, why are activated neurons restricted to non-vestibulo-ocular and vestibulo-spinal regions?

The most likely explanation for this discrepancy derives from a report by Courjon et al. (1987) in which a wide variety of central vestibular neurons were activated by galvanic stimulation. Units that responded to rotation promptly habituated, while those units that were non-responsive to rotation, which were presumably otolith units, continued to fire in response to GVS. We propose that this canal-specific response habituation underlies the apparent inconsistency between the global vestibular activation by GVS and the otolith-predominant neural and behavioral responses. Moreover, the c-Fos localization findings can be further interpreted in this light, since c-Fos protein is not manifest in neurons that are tonically inhibited (Chan and Sawchenko, 1994). Many vestibular neurons that participate in vestibulo-ocular and vestibulospinal reflexes receive formidable direct inhibition from cerebellar Purkinje cells and/or inhibitory commissural and intraVNC fibers (for review, see Holstein, 2011). These neurons are not likely to express c-Fos protein, even though they may initially be 
activated by sGVS. Further still, while neurons that receive predominantly excitatory input and some cells under conditions of release from tonic inhibition show c-Fos expression in response to appropriate stimuli, other disinhibited neurons do not express c-Fos induction (for review, see Kovács, 2008), and c-Fos is rarely observed in large motor neurons of the brainstem (Chan and Sawchenko, 1994). As a result, vestibulo-ocular, vestibulo-spinal, and vestibulo-colic motor neurons present in subregions of the VNC should not be expected to accumulate c-Fos protein. On the basis of this analysis, we conclude that while sGVS does indeed activate the entire vestibular nerve, only the otolith system expresses a persistent behavioral and neural response due to the habituation of the canal-related units and the attendant inhibition of vestibular neuronal populations. It is likely that the habituation of the semicircular canal induced activity originates in the cerebellum, but this remains to be determined.

\section{ACKNOWLEDGMENTS}

The research underlying this opinion article was supported by NIH grants DC008846 (Gay R. Holstein), DC004996 (Sergei B. Yakushin), and Core Center DC05204 (Bernard Cohen).

\section{REFERENCES}

Abe, C., Tanaka, K., Awazu, C., and Morita, H. (2009). Galvanic vestibular stimulation counteracts hypergravity-induced plastic alteration of vestibulo-cardiovascular reflex in rats. J. Appl. Physiol. 107, 1089-1094.

Bent, L. R., Bolton, P. S., and Macefield, V. G. (2006). Modulation of muscle sympathetic bursts by sinusoidal galvanic vestibular stimulation in human subjects. Exp. Brain Res. 174, 701-711.

Chan, R. K., and Sawchenko, P. E. (1994). Spatially and temporally differentiated patterns of c-for expression in brainstem catecholaminergic cell groups induced by cardiovascular challenges in the rat. J. Comp. Neurol. 348, 433-460.

Cohen, B., Martinelli, G. P., Ogorodnikov, D., Xiang, Y., Raphan, T., Holstein, G. R., and Yakushin, S. B. (2011). Sinusoidal galvanic vestibular stimulation (sGVS) induces a vasovagal response in the rat. Exp. Brain Res. 210, 45-55.

Cohen, B., Suzuki, J., and Bender, M. B. (1965). Nystagmus induced by electric stimulation of ampullary nerves. Acta Otolaryngol. 60, 422-436.
Courjon, J. H., Precht, W., and Sirkin, D. W. (1987) Vestibular nerve and nuclei unit responses and eye movement responses to repetitive galvanic stimulation of the labyrinth in the rat. Exp. Brain Res. 66, 41-48.

Curthoys, I. S. (2009). A critical review of the neurophysiological evidence underlying clinical vestibular testing using sound, vibration and galvanic stimuli. Clin. Neurophysiol. 121, 132-144.

Ezure, K., Cohen, M.S., and Wilson, V.J. (1983). Response of cat semicircular canal afferents to sinusoidal polarizing currents: implications for input-output properties of second-order neurons. J. Neurophysiol. 49, 639-648.

Fitzpatrick, R. C., and Day, B. L. (2004). Probing the human vestibular system with galvanic stimulation. J. Appl. Physiol. 96, 2301-2316.

Galvani, L. (1791). De Viribus Electricitatis in Motu Musculari Commentarius. Institute of Sciences at Bologna, Bologna.

Goldberg, J. M., Smith, C. E., and Fernandez, C. (1984). Relation between discharge regularity and responses to externally applied galvanic currents in vestibular nerve afferents of the squirrel monkey. J. Neurophysiol. 51, 1236-1256.

Grewal, T., James, C., and Macefield,V.G. (2009). Frequencydependent modulation of muscle sympathetic nerve activity by sinusoidal galvanic vestibular stimulation in human subjects. Exp. Brain Res. 197, 379-386.

Guedry, F. E. (1974). "Psychophysics of vestibular sensation," in Handbook of Sensory Physiology, ed. H. H. Kornhuber (Berlin, Heidelberg, New York: Springer Verlag), 3-154.

Holstein, G. R. (2011). “The Vestibular System,” in The Human Nervous System, 3rd Edn, eds J. Mai and G. Paxinos (London: Elsevier), 1239-1269.

James, C., and Macefield, V.G. (2010). Competitive interactions between vestibular and cardiac rhythms in the modulation of muscle sympathetic nerve activity. Auton. Neurosci. 158, 127-131.

James, C., Statis, A., and Macefield, V.G. (2010). Vestibular and pulse-related modulation of skin sympathetic nerve activity during sinusoidal galvanic vestibular stimulation in human subjects. Exp. Brain Res. 202, 291-298.

Kaufman, G. D., and Perachio, A. A. (1994). Translabyrinthine electrical stimulation for the induction of immediate-early genes in the gerbil brainstem. Brain Res. 646.

Kerman, I. A., Enquist, L. W., Watson, S. J., and Yates, B. J. (2003). Brainstem substrates of sympatho-motor circuitry identified using trans-synaptic tracing with pseudorabies virus recombinants. J. Neurosci. 23, 4657-4666.

Kovács, K. J. (2008). Measurement of immediate-early gene activation- c-fos and beyond. J. Neuroendocrinol. 20, 665-672.

Lau, L. D., Sparto, P. J., Furman, J. M., and Redfern, M. S. (2003). The steady-state postural responses to continuous sinusoidal galvanic stimulation. Gait Posture $18,64-72$.
Macdougall, H. G., Brizuela, A. E., Burgess, A. M., Curthoys, I. S., and Halmagyi, G. M. (2005). Patient and normal three-dimensional eye-movement reesponses to maintained (DC) surface galvanic vestibular stimulation. Otol. Neurotol. 26, 500-511.

Mach, E. (1875). Grundlinean der Lehre von den Bewegungsemphindungen. Leipzig: Endelmann.

Marshburn, T. H., Kaufman, G. D., Purcell, I. M., and Perachio, A.A. (1997). Saccule contribution to immediate early gene induction in the gerbil brainstem with posterior canal galvanic or hypergravity stimulation. Brain Res. 761, 51-58.

Minor, L. B., and Goldberg, J. M. (1991). Vestibular-nerve inputs to the vestibulo-ocular reflex: a functionalablation study in the squirrel monkey. J. Neurosci. 11, 1636-1648.

Peterson, B. W., Fukushima, K., Hirai, N., Schor, R. H., and Wilson, V.J. (1980). Responses of vestibulospinal and reticulospinal neurons to sinusoidal vestibular stimulation. J. Neurophysiol. 43, 1236-1250.

Séverac Cauquil, A., Faldon, M., Popov, K., Day, B. L., and Bronstein,A.M. (2003). Short-latency eye movements evoked by near-threshold galvanic vestibular stimulation. Exp. Brain Res. 148, 414-418.

Watson, S. R., Brizuela, A. E., Curthoys, I. S., Colebatch, J. G., Macdougall, H. G., and Halmagyi, G. M. (1998). Maintained ocular torsion produced by bilateral and unilateral galvanic (DC) vestibular stimulation in humans. Exp. Brain Res. 122, 453-458.

Wilson, V. J., Peterson, B. W., Fukushima, K., Hirai, N., and Uchino, Y. (1979). Analysis of vestibulocollic reflexes by sinusoidal polarization of vestibular afferent fibers. J. Neurophysiol. 42, 331-346.

Woodring, S. F., Rossiter, C. D., and Yates, B. J. (1997). Pressor response elicited by nose-up vestibular stimulation in cats. Exp. Brain Res. 113, 165-168.

Yates, B. J. (1992). Vestibular influences on the sympathetic nervous system. Brain Res. Rev. 17, 51-59.

Zhu, H., Jordan, J. R., Hardy, S. P. G., Fulcher, B., Childress, C., Varner, C., Windham, B., Fjeffcoat, B., Rockhold, R. W., and Zhou, W. (2007). Linear acceleration-evoked cardiovascular responses in awake rats. J. Appl. Physiol. 103, 646-654

Zink, R., Steddin, S., Weiss, A., Brandt, T., and Dieterich, M. (1997). Galvanic vestibular stimulation in humans: effects on otolith function in roll. Neurosci. Lett. 232, 171-174.

Received: 08 December 2011; accepted: 21 December 2011; published online: 06 January 2012.

Citation: Cohen B, Yakushin SB and Holstein GR (2012)

What does galvanic vestibular stimulation actually activate? Front. Neur. 2:90. doi: 10.3389/fneur.2011.00090

This article was submitted to Frontiers in Neuro-otology, a specialty of Frontiers in Neurology.

Copyright (c) 2012 Cohen, Yakushin and Holstein. This is an open-access article distributed under the terms of the Creative Commons Attribution Non Commercial License, which permits non-commercial use, distribution, and reproduction in other forums, provided the original authors and source are credited. 